\title{
A Study of Aerosols in Pacific Air Masses
}

\author{
C. E. Junge \\ Max Planck Insitht für Chemie, Mainz, Germany \\ ANd Elamer Robinson and F. L. Ludwig \\ Slanford Rescarch Institule, Menlo Park, Calif. \\ (Mamuscript received 31 January 1969, in revised form on 11 March 1969)
}

\begin{abstract}
This paper describes a program of aerosol measurements made in the fall of 1965 at Cape Blanco and Crater Lake, Ore. Aerosol size distributions were determined with a Royco light-scattering type particle counter and with condensation nuclei counters. Size distributions at Crater Lake $(2200 \mathrm{~m}$ altitude) were found to be well approximated by power law distributions with exponents between 3 and 4 . The Cape Blanco data agree well with earlier measurements of sea-spray aerosol size distributions. A Goetz aerosol centrifuge was used, in conjunction with filter sampling, to determine the size distribution of the chloride- and sulfur-compound fractions of the aerosol.

At Crater Lake, sulfur-to-chloride ratios of about 8 were observed and considerable concentrations of other materials could be inferred. The data indicate that significant amounts of sea-spray aerosol did not penetrate upward to altitudes $>2000 \mathrm{~m}$. The aerosols identified with these $2000 \mathrm{~m}$ tropospheric levels are believed to be aged acrosols from contincntal sources. High-altitude tropospheric aerosols were also observed at Crater Lake during periods of subsidence; their concentrations were lower than those found under other synoptic weather conditions. The power law representations for subsidence aerosols had lower exponential values than those for the lower altitude tropospheric aerosols.
\end{abstract}

\section{Introduction}

The upper half of the troposphere over continental areas and most of the troposphere over the oceans are filled with a rather diluted aerosol with total particle concentrations in the range of $200-800 \mathrm{~cm}^{-3}$. Although about three-quarters of the troposphere is filled with these background aerosols, we know almost nothing about their size distributions and their chemical composition. We believe that datal of this kind from remote areas are sufficiently valuable for the understanding of the nature of tropospheric atosols that even limited studies warrant reporting. This paper covers size distribution data for the radius range $0.01<r \leqslant 4 \mu m$, the upper limit being variable due to low concentrations, and also some microanalytical data on the sulfate and chloride mass fractions of the particulates over the same size interval $0.01 \leqq r \leqq \mu m$ in Pacific air masses on the coast of Oregon. The details of the study are available elsewhere (Junge, 1966).

Datal were taken at Cape Blanco, Ore, on the coast about $160 \mathrm{~km}$ north of the (ablifornia border and on $\mathrm{Mt}$. Mazama in Crater Lake National Park about $160 \mathrm{~km}$ east of Cape Blanco at an altitude of $2200 \mathrm{~m}$. The Cape Blanco sampling site was at the Coast Guard station atop steep cliffs about $65 \mathrm{~m}$ above the sea; local surf influences were minimal. The area between Cape Blanco and Crater Lake is forested and has only a few small communities. The air mass trajectories from the north
Pacific to these remote locations are such that the data are considered generally representative of uncontaminated surface and upper level trospopheric air masses.

The basic instrumentation for this work consisted of a Royco PC200A photometric particle counter, a Goetz aerosol centrifuge, air filters, and two Aitken nuclei counters. One of the nuclei counters was a General Electric design and one an improved version of the Scholz counter (Kleinschmidt, 1935). The Royco counter provided measurements of size distributions in the radius range of $0.15 \leqslant r \leqslant 4 \mu \mathrm{m}$ and the nuclei counters gave information of the total particle concentrations including those below this size. We are aware of the various questions which have arisen about the use of photometric counters (e.g., Whitby and Vomela, 1967; Hodkinson and Greenfield, 1965). The resolution is less than that indicated by the number of channels so that some smoothing of the distributions occurs. The absolute concentrations may be somewhat in error beciuse of refractive index and shape differences between at mospheric aterosols and the latex spheres used for calibration, but the general shape of the distributions is as good as the dati obtained with most other methods. For particles larger than $r=1.0 \mu \mathrm{m}$ the concentrations in our experiments were sometimes so low that valid size distributions could not be obtained.

The nuclei concentration data from the Scholz counter were considered more reliable than those from 
the G. E. instrument since the Scholz counter is an absolute instrument built to cover low concentrations. The two instruments were carefully compared and some systematic deviations were found. The G. E. counts were corrected to reflect the differences found in the comparison, so the readings are compatible with the Scholz counts.

The Goetz aerosol centrifuge was used to collect samples from which size distributions could be determined for sulfur- and chloride-containing particulates. The techniques used for the sulfur-containing compounds have been described by Ludwig and Robinson $(1965,1968)$. The chloride size distributions were determined from the same samples. The chemical analyses for chlorides were made by the coulometric method described by Coulson and Cavanagh (1960). All methods had been previously used in urban sampling programs. In this program there were some refinements in cleaning techniques to reduce backgrounds, but even with these refinements it was necessary to operate for long periods to accumulate samples large enough for analysis.

Only one sample was collected with the centrifuge over the six days of operation at Crater Lake, this sample representing $45 \mathrm{hr}$ of operation during which $19.6 \mathrm{~m}^{3}$ of air passed through the instrument. Two samples were collected at Cape Blanco, each requiring about $20 \mathrm{hr}$ of collection. Because of the long sampling times the resulting size distributions are not representative of one type of weather situation, but rather a mixture. In this paper the Royco and condensation nuclei data are emphasized because they are more plentiful and can be discussed in terms of their variations with changes in the meteorological situation. The sulfur- and chloride-compound data cannot be treated in this manner and are therefore discussed only briefly.

The electrical power for the instruments came from a portable gasoline motor generator (kept downwind of the samplers) at Crater Lake and from available power Cape Blanco.

Meteorological interpretations and air mass origins have been inferred from our observations at the sampling site, from the Medford, Ore., radiosonde data, and from trajectories based on U. S. Weather Bureau surface and 700-mb analyses.

Sampling was done during the periods 26-30 September 1965 and 28 October to 2 November 1965 at Crater Lake, and 5-9 November 1965 at Cape Blanco.

\section{Size distribution data}

The size distribution data obtained at Cape Blanco and Crater Lake are plotted in Figs. 1-3. The Royco data were converted to the familiar $d N^{T} / d(\log r)$ values and then extrapolated to $0.1 \mu \mathrm{m}$. The condensation nuclei counts were assumed to cover the range $0.01 \leqslant r \leqslant 0.1 \mu \mathrm{m}$; and the actual counts were plotted as horizontal lines. This representation of the data serves

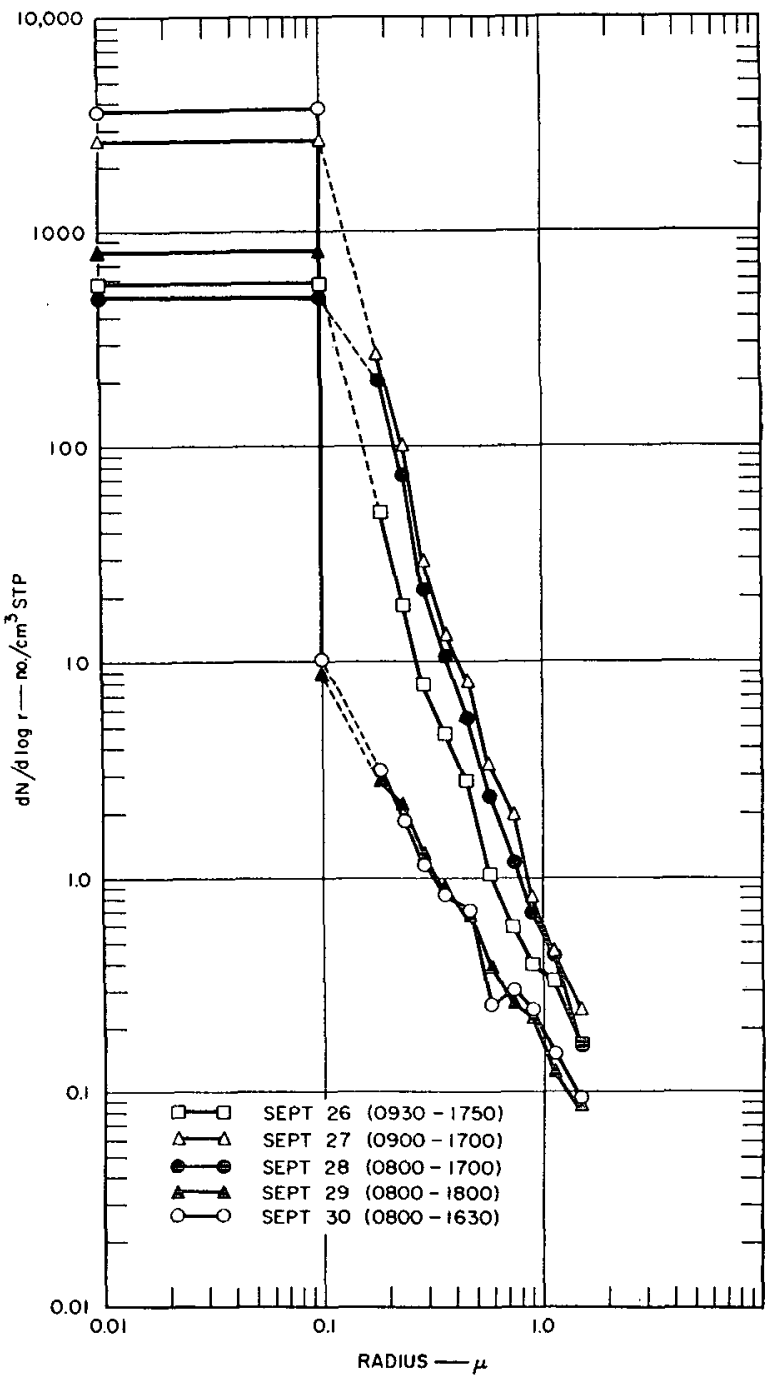

FIG. 1. Daily averages of aerosol size distributions at Crater Lake, 26-30 September 1965.

as a rough approximation to the actual size distribution below $0.15 \mu \mathrm{m}$ and it is in agreement with earlier findings that the aerosol spectrum is continuous down to $0.01 \mu \mathrm{m}$.

On most days the Royco distributions did not change much through the daytime sampling periods so that it was quite realistic to plot the daily average values shown in Figs. 1-3. The local standard times during which the measurements were made are given in parentheses. The weather situation during the three sampling periods was as follows:

1) 26-30 September 1965, Crater Lake. A quasistationary high over the eastern Pacific with a $500-\mathrm{mb}$ trough extended westward from Central Canada. On 26 September weak subsidence was noted. With more pronounced influx of air from the north on 27 and 28 September, the inversion lifted to above station level. 


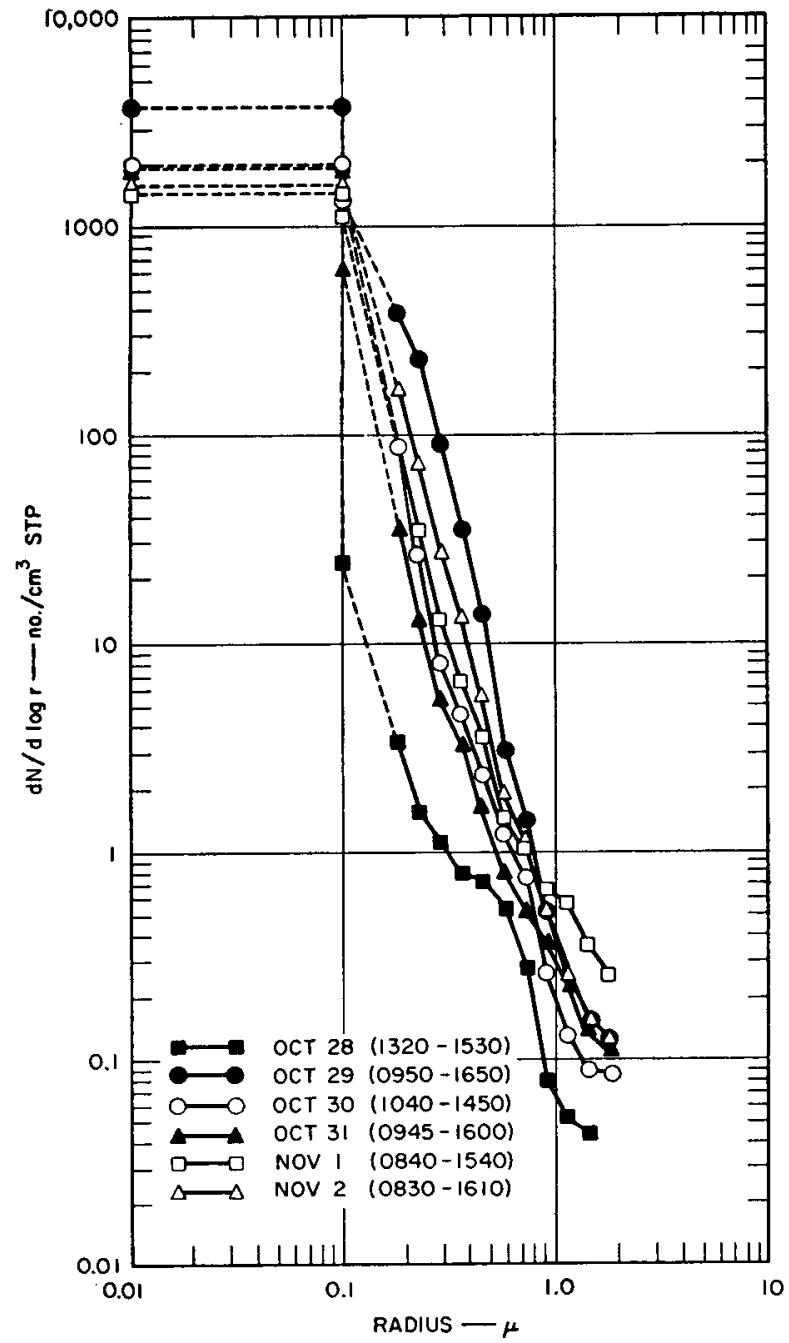

Fig. 2. Daily averages of aerosol size distributions at Crater Lake, 28 October to 2 November 1965.

Despite diurnal variations, the concentration averages for these days are almost identical, indicating the presence of the same general air mass on these days, in agreement with the synoptic situation. On 29 and 30 September an extension of the Pacific high to the east was accompanied by strong subsidence, with a pronounced inversion below the sampling section and visibility $\geqslant 100 \mathrm{~m}$. Again the size distributions are almost identical for these two days.

2) 28 October to 2 November 1965, Crater Lake. A high pressure system located over the western part of the U. S. caused light-to-moderate influx of Pacific air at $700 \mathrm{mb}$ with varying amounts of high clouds and generally good visibility. Subsidence occurred on 28 October after passage of a cold front from the west. There seem to have been no very pronounced differences in air mass influx on other days, in agreement with relatively uniform size distributions and Aitken nuclei counts. The lowest concentrations were observed on 28
October and 29 and 30 September and the particle distributions differ from those of the other synoptic situations. They are believed to represent the upper tropospheric aerosol brought to the site by subsidence. During 28 October to 2 November, Crater Lake data are believed to be representative of Pacific air masses at an altitude of $\sim 2200 \mathrm{~m}$ and are probably as representative as can be obtained without aircraft support. The trajectories always indicated rather direct maritime origin of the air masses with only short passages over southern Oregon or northern California.

3) 5-9 November 1965, Cape Blanco. A high pressure ridge across southern Oregon, connected high pressure systems over north central United States and off the coast of Mexico. Surface winds at Cape Blanco were from the south to southwest, obviously channeled by the steep north-south coastal cliffs that produce southerly wind directions for a variety of pressure gradients. The wind and weather observations indicate

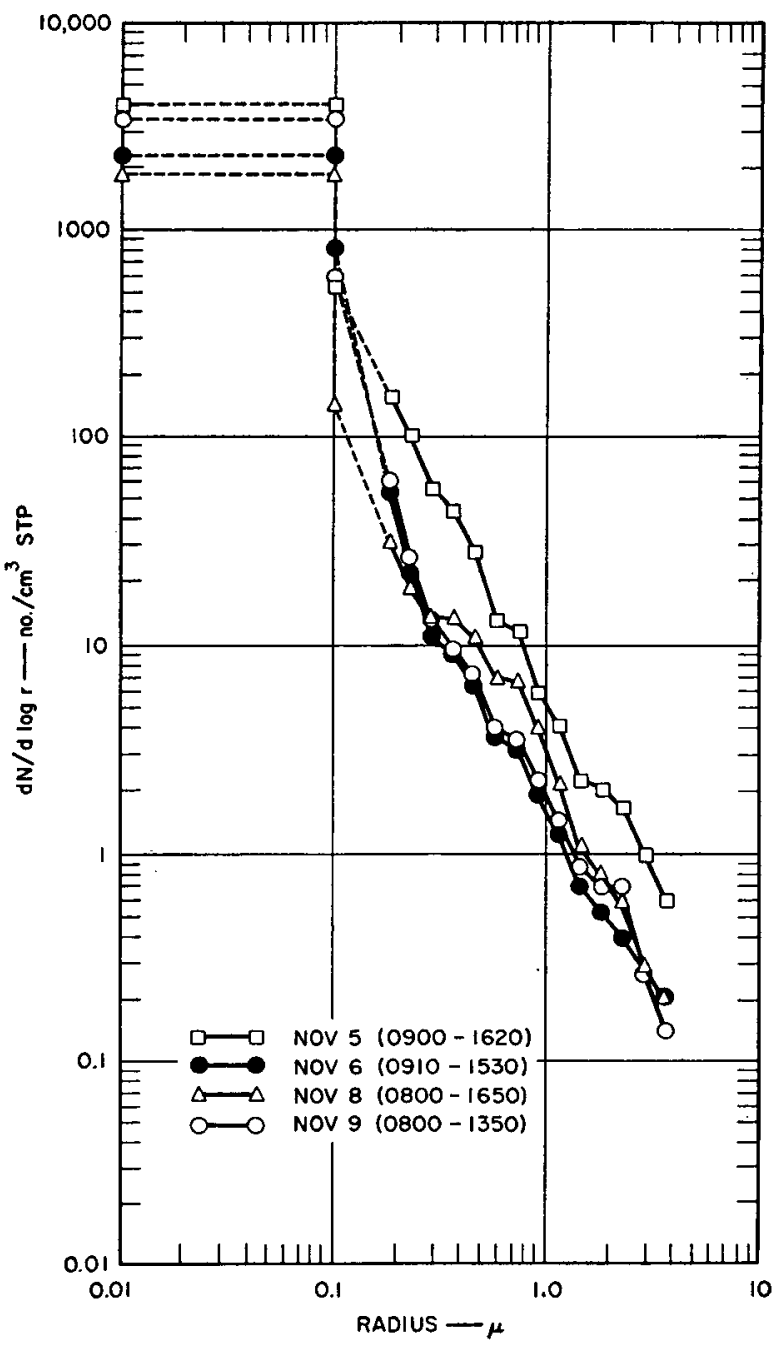

FIG. 3. Daily averages of aerosol size distributions at Cape Blanco, 5-9 November 1965. 
that the data are fairly representative of eastern Pacific conditions without significant local contamination.

For radii $>0.15 \mu \mathrm{m}$ the distributions for most of the days shown in Figs. 1 and 2 can be well approximated by a power law function of the form

$$
\frac{d N}{d(\log r)}=C\left(\frac{r}{r_{0}}\right)^{\nu^{*}},
$$

where $r_{0}$ is the reference radius, $C \log$ density at $r_{0}$, and $\nu^{*}$ a constant. At Crater Lake, $\nu^{*}$ scatters around 3.5 except for the three days of subsidence where it is close to 2 . Since the Royco counter tends to smooth the curves, it might be concluded from these data that there is some structure in the distributions, at least in the range $0.2 \leqslant r \leqslant 2 \mu \mathrm{m}$, and that in most cases the distributions do not exactly fit a smooth power law representation. The slow variations in time and space of the concentration and slope of these tropospheric background aerosols suggest that their size distributions represent equilibria among supply, modification and removal processes with long characteristic times. Because of the extremely low concentrations, thermal coagulation and thus Friedlander's (1960) concept of self-preserving distributions, cannot be involved to any degree. Equilibrium distributions, however, should be expected to be rather smooth and any detailed structure would point to the recent addition of fresh material.

Aitken nuclei concentrations from both sampling periods at Crater Lake are rather high for air masses of maritime origin, generally greater than $1000 \mathrm{~cm}^{-3}$; there are no obvious correlations to the synoptic situation. In general, the particle concentrations around $1 \mu$ vary less than the smaller ones, in agreement with previous experience.

The Cape Blanco data showed greater hourly fluctuations and the averages in Fig. 3 have greater deviations from the power law representation than do the Crater Lake data. Concentrations generally increase monotonically with decreasing particle radius, but the data for 8 November show a secondary peak around $r=0.4$ $\mu \mathrm{m}$. Average Cape Blanco Aitken concentrations are higher than Crater Lake's. Some land source contamination is possible but is unlikely since high counts were found even when the air's origin was almost certainly and exclusively maritime.

The local surf was not a factor in the nuclei counts. On 9 November nuclei counts were made at several elevations from the lighthouse sampling site down to the edge of the water $65 \mathrm{~m}$ below; the surf at the time was not strong. There was no significant difference between surf area and lighthouse nuclei concentrations. Thus, the observed nuclei concentrations appear to represent maritime surface air masses during the sampling period, not surf-generated nuclei.

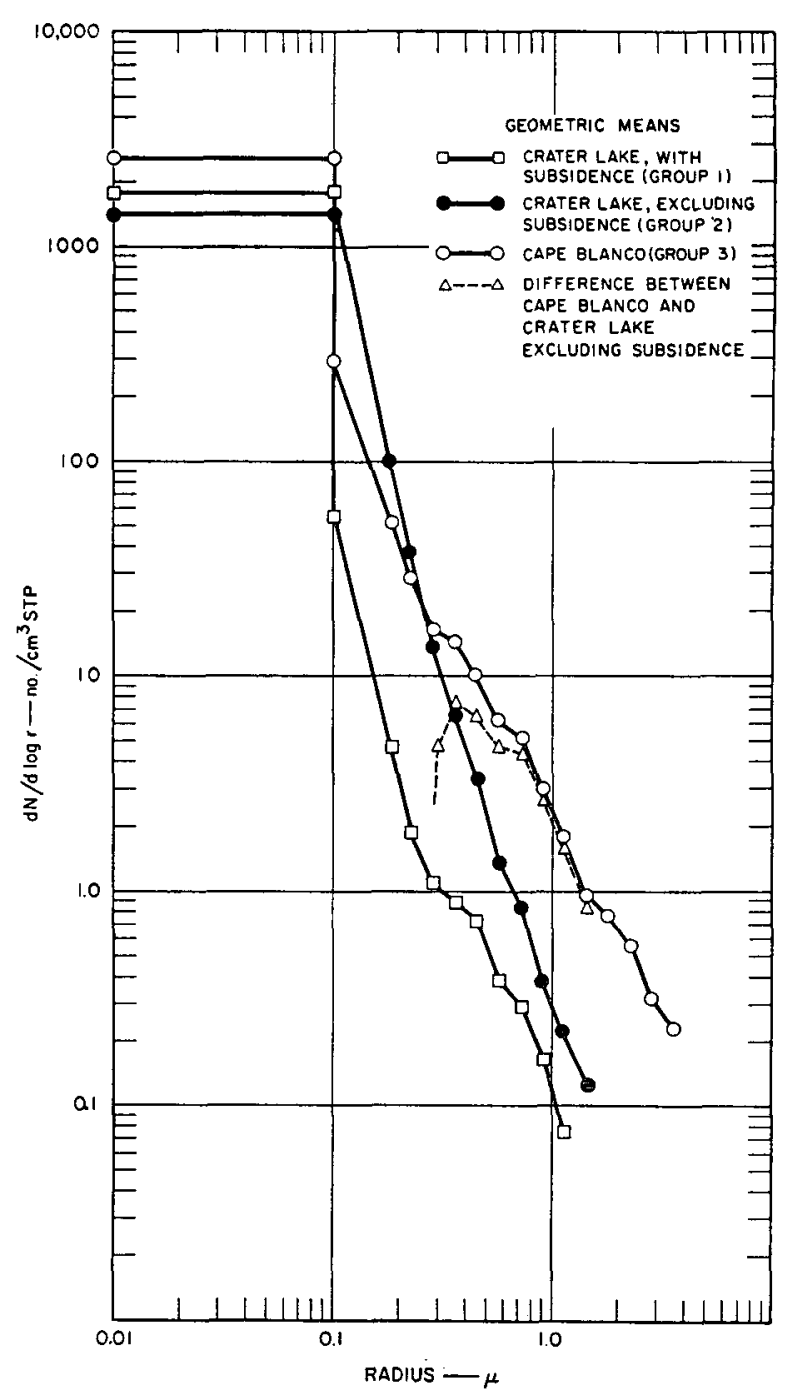

FIG. 4. Geometric mean size distributions for Crater Lake, with and without subsidence, and for Cape Blanco. In addition, the difference between the data from Cape Blanco and those at Crater Lake excluding subsidence is plotted.

\section{Discussion of size distribution data}

To obtain reasonably representative distributions for Pacific air masses, the data were grouped as follows: 1) Crater Lake, with strong subsidence, 29 and 30 September and 28 October; 2) Crater Lake, excluding subsidence; and 3) Cape Blanco, all data. Fig. 4 shows the geometrically averaged distributions for these groups. The standard geometric deviations of observed daily average concentrations are about $1.5-2.0$, except for the larger sizes. For these larger sizes there are the statistical uncertainties due to the sampling of small numbers of particles and hence the standard deviations are larger.

The Crater Lake "excluding subsidence" distribution is closest to a power law distribution, with $\nu^{*}=3.2$. The other two groups deviate more from the power law, but 


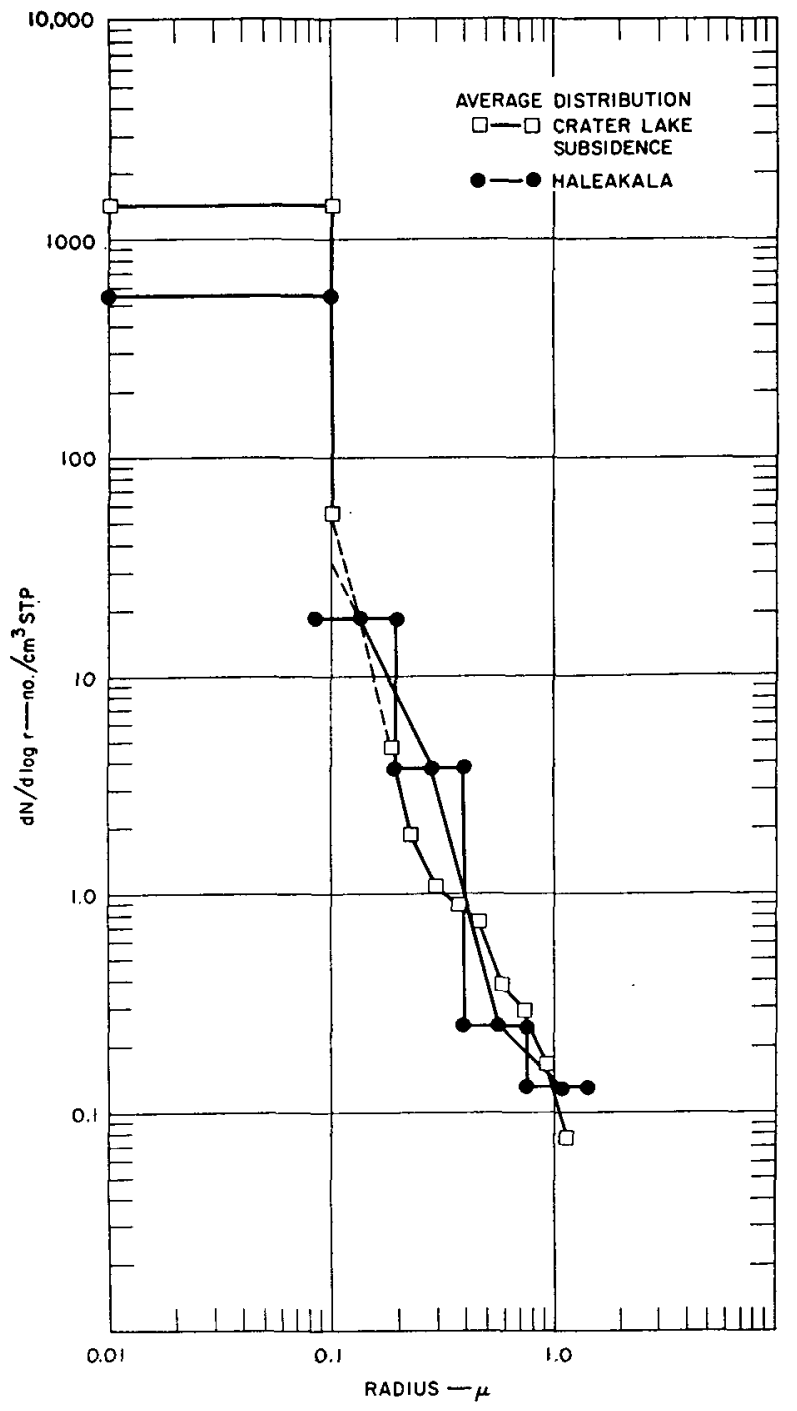

FIG. 5. Comparison between Crater Lake with subsidence and impactor data for Haleakala, Hawaii.

$\nu^{*} \cong 2$ approximates them. The data suggest a continuous size spectrum from $r=1 \mu \mathrm{m}$ to below $0.01 \mu \mathrm{m}$.

Since groups 2 and 3 represent Pacific air masses at two different altitudes, the differences between the two sets of data may show the Cape Blanco sea-spray (not surf) component. Although the data were obtained at different times at the two places, we believe that they are sufficiently representative to justify the comparison shown in Fig. 4. The $0.2 \mu \mathrm{m}$ concentrations at the two sites are almost the same, but the Cape Blanco concentrations are definitely higher for larger sizes. This difference is almost identical to Junge's (1963, Fig. 26) average sea-spray distribution based on the data of Woodcock, Metnieks, and others. At Cape Blanco local surf influences were largely excluded by the location of the sampler; thus, the sea-spray component of the Cape Blanco data may be representative of average surface conditions in Pacific air masses. The differences between Cape Blanco and the Crater Lake data suggest that the sea-spray aerosol in Pacific air, at least during these sampling periods, was restricted to the layer below $2 \mathrm{~km}$. This is confirmed by our chloride analyses (discussed in Section 4).

The Aitken particle concentrations observed in our studies differ surprisingly from measurements over the Atlantic (Lettau, 1939; Day, 1955). The Atlantic clean air mass nuclei concentrations were about $300 \mathrm{~cm}^{-3}$ in tropical and subtropical latitudes, much the same as those found above $5 \mathrm{~km}$ over the central U. S. (Junge, 1961). Measurements with the G. E. counter in the North Altantic during the fall of 1968 showed much higher values than $300 \mathrm{~cm}^{-3}$, but these data have not yet been fully evaluated. If correct, these higher counts in the northern middle latitudes over the Atlantic would suggest the influence of anthropogenic sources. Average concentrations between 1000 and $2000 \mathrm{~cm}^{-3}$ were found at Cape Blanco and most days at Crater Lake. Even during subsidence, Crater Lake concentrations did not drop below $700 \mathrm{~cm}^{-3}$. Fig. 5 presents measurements taken at Haleakala, Hawaii (Bullrich et al., 1966). These were obtained above the trade-wind inversion at an elevation of $3050 \mathrm{~m}$ above sea level. The Aitken counts are about $600 \mathrm{~cm}^{-3}$. Since our counts using the two different counters are fairly reliable and consistent, it appears that there may be some source of Aitken nuclei for air masses over the eastern Pacific at these latitudes.

For sizes $>0.1 \mu \mathrm{m}$, the Haleakala size distribution measurements of Bullrich et al. (1966) are quite similar to those during subsidence at Crater Lake. This supports the concept of a rather uniform upper tropospheric background aerosol.

\section{Chemical Data}

Concurrently with the size distribution studies, samples were collected to provide information about the chemical nature of the aerosol as a function of size. The Goetz aerosol centrifuge and glass fiber filters were used, and analyses were made for sulfur and chloride. The very low concentrations found in these remote areas presented many problems. By careful preparation of the stainless steel linings in the Goet $z$ centrifuge and of the filters, which were run parallel to the centrifuge or as a back up, we were able to reduce the analytical background to the following levels:

$\begin{array}{lcc} & \begin{array}{c}\text { Each segment } \\ \text { of lining } \\ (\mu \mathrm{g})\end{array} & \begin{array}{c}\text { Filter } \\ (\mu \mathrm{g})\end{array} \\ \text { Sulfur } & \sim 0.1 & \sim 1 \\ \text { Chloride } & \sim 0.3 & \sim 1.7\end{array}$

Preliminary samples during the first sampling period indicated that even with these backgrounds only very long sampling times could produce samples which could give reasonable.net quantities of material and hence 
TABLE 1. Comparison of the size distributions of sulfur.

\begin{tabular}{|c|c|c|c|c|c|c|}
\hline \multirow[b]{2}{*}{$\begin{array}{l}\text { Radius of sulfur } \\
\text { particles } \\
(\mu \mathrm{m})\end{array}$} & \multicolumn{2}{|c|}{$\begin{array}{c}\text { Sample } 1 \\
\text { Crater Lake }\end{array}$} & \multicolumn{2}{|c|}{$\begin{array}{c}\text { Sample } 2 \\
\text { Cape Blanco }\end{array}$} & \multicolumn{2}{|c|}{$\begin{array}{c}\text { Sample } 3 \\
\text { Cape Blanco }\end{array}$} \\
\hline & $\begin{array}{c}\text { Cumulative } \\
\text { distribution } \\
(\%)\end{array}$ & $\begin{array}{c}\text { Absolute } \\
\text { concentration } \\
\left(\mu \mathrm{g} \mathrm{m}^{-3} \text { STP }\right)\end{array}$ & $\begin{array}{c}\text { Cumulative } \\
\text { distribution } \\
(\%)\end{array}$ & $\begin{array}{c}\text { Absolute } \\
\text { concentration } \\
\left(\mu \mathrm{g} \mathrm{m}^{-3} \mathrm{STP}\right)\end{array}$ & $\begin{array}{c}\text { Cumulative } \\
\text { distribution } \\
(\%)\end{array}$ & $\begin{array}{c}\text { Absolute } \\
\text { concentration } \\
\left(\mu \mathrm{g} \mathrm{m}^{-3} \mathrm{STP}\right)\end{array}$ \\
\hline$\leqq 0.025$ & 9 & 0.041 & 4 & 0.043 & 4 & 0.027 \\
\hline$\leqq 0.05$ & 20 & 0.090 & 7 & 0.076 & 7 & 0.048 \\
\hline$\leqq 0.10$ & 39 & 0.176 & 14 & 0.151 & 11 & 0.076 \\
\hline$\leqq 0.25$ & 69 & 0.310 & 22 & 0.238 & 17 & 0.118 \\
\hline$\leqq 0.5$ & 80 & 0.360 & 25 & 0.270 & 20 & 0.138 \\
\hline$\leqq 1.0$ & 86 & 0.386 & 27 & 0.292 & 22 & 0.152 \\
\hline$\geqq 1.0$ & 14 & 0.064 & 73 & 0.788 & 78 & 0.538 \\
\hline Total & 100 & 0.450 & 100 & 1.080 & 100 & 0.690 \\
\hline
\end{tabular}

acceptable accuracies of analysis. As a result it was necessary to collect samples over periods of several days.

The Goetz centrifuge was operated with a back-up filter in such a way that the filter would not disturb the flow through the centrifuge. In addition, two sets of filters were used to sample the total aerosol directly. One was covered with a 0.3 -inch entrance tube and one was open-faced. The data from Cape Blanco indicated that there was loss of giant particles at the entrance of the centrifuge and at the inlet of the partially covered filter; therefore, we accepted the open-faced filter data as correct for total concentration, and these values were used for the size distribution calculations. The following samples were taken:

1) Crater Lake, 28 October to 2 November, $45 \mathrm{hr}$

A. S. sample volume, $19.6 \mathrm{~m}^{3} \mathrm{STP}$

Filter sample volume, $44.4 \mathrm{~m}^{3} \mathrm{STP}$

Total sulfur concentration, $0.45 \mu \mathrm{g} \mathrm{m}^{-3}$

Total chloride concentration, $0.06 \mu \mathrm{g} \mathrm{m}^{-3}$

2) Cape Blanco, 4-6 November, $20 \mathrm{hr}$

A. S. sample volume, $10.5 \mathrm{~m}^{3} \mathrm{STP}$

Filter sample volume, $16.4 \mathrm{~m}^{3} \mathrm{STP}$

Total sulfur concentration, $1.08 \mu \mathrm{g} \mathrm{m}^{-3}$

Total chloride concentration, $32.4 \mu \mathrm{g} \mathrm{m}^{-3}$

3) Cape Blanco, 8-9 November, $20 \mathrm{hr}$

A. S. sample volume, $10.4 \mathrm{~m}^{3} \mathrm{STP}$

Filter sample volume, $14.4 \mathrm{~m}^{3} \mathrm{STP}$

Total sulfur concentration, $0.69 \mu \mathrm{g} \mathrm{m}^{-3}$

Total chloride concentration, $18.6 \mu \mathrm{g} \mathrm{m}^{-3}$
After collection of the sample and prior to chemical analysis, the Goetz centrifuge linings were cut into strips. The chemical analyses were treated according to principles described by Ludwig and Robinson (1965, 1968) to give data for the size ranges listed in Tables 1 and 2 .

We are well aware of the fact that there are too few data to support more than very tentative conclusions, but since some of the data are quite novel, while some confirm earlier data, we think that they warrant this reporting and a brief discussion.

The size distributions of sulfur concentration for $r \leqslant 1 \mu \mathrm{m}$ are similar for all three samples, but for $r \geqslant 1 \mu \mathrm{m}$ the relative masses of sulfur are higher by a factor of 5 in samples 2) and 3). In this size range the $\mathrm{Cl}^{-} / \mathrm{SO}_{4}=$ ratio (assuming the sulfur is in the form of sulfate) is 12.6 for sample 2) and 11.3 for sample 3). These high ratios indicate a seawater origin of this aerosol is more likely than a continental origin. The seawater ratio is 7.3. Earlier data have shown that the sea spray is masswise essentially restricted to $r \geqslant 1 \mu \mathrm{m}$ and that at the same time fractionation in this size range is not very pronounced.

A comparison of the chemical data and the size distribution data indicates that for $r \leqslant 1 \mu \mathrm{m}$ about $25 \%$ of the aerosol volume can be accounted for by sulfate.

Table 2. Comparison of the size distributions of chloride.

\begin{tabular}{|c|c|c|c|c|c|c|}
\hline \multirow[b]{2}{*}{$\begin{array}{l}\text { Radius of chloride } \\
\text { particles } \\
(\mu \mathrm{m})\end{array}$} & \multicolumn{2}{|c|}{$\begin{array}{c}\text { Sample } 1 \\
\text { Crater Lake }\end{array}$} & \multicolumn{2}{|c|}{$\begin{array}{c}\text { Sample } 2 \\
\text { Cape Blanco }\end{array}$} & \multicolumn{2}{|c|}{$\begin{array}{c}\text { Sample } 3 \\
\text { Cape Blanco }\end{array}$} \\
\hline & $\begin{array}{c}\text { Cumulative } \\
\text { distribution } \\
(\%)\end{array}$ & $\begin{array}{c}\text { Absolute } \\
\text { concentration } \\
\left(\mu \mathrm{g} \mathrm{m}^{-3} \mathrm{STP}\right)\end{array}$ & $\begin{array}{c}\text { Cumulative } \\
\text { distribution } \\
(\%)\end{array}$ & $\begin{array}{c}\text { Absolute } \\
\text { concentration } \\
\left(\mu \mathrm{g} \mathrm{m}^{-3} \mathrm{STP}\right)\end{array}$ & $\begin{array}{c}\text { Cumulative } \\
\text { distribution } \\
(\%)\end{array}$ & $\begin{array}{c}\text { Absolute } \\
\text { concentration } \\
\left(\mu \mathrm{g} \mathrm{m}^{-3} \mathrm{STP}\right)\end{array}$ \\
\hline$\leqq 0.025$ & - & - & 2.8 & 0.91 & - & - \\
\hline$\leqq 0.05$ & 2 & 0.0012 & 4.2 & 1.36 & - & - \\
\hline$\leqq 0.10$ & 9 & 0.0054 & 5.5 & 1.78 & 0.2 & 0.037 \\
\hline$\leqq 0.25$ & 59 & 0.0350 & 6.8 & 2.2 & 1.7 & 0.316 \\
\hline$\leqq 0.50$ & 81 & 0.0485 & 7.5 & 2.4 & 1.9 & 0.354 \\
\hline$\leqq 1.00$ & 97 & 0.0581 & 8.0 & 2.6 & 2.0 & 0.372 \\
\hline$\geqq 1.00$ & 3 & 0.0019 & 92 & 29.8 & 98 & 18.2 \\
\hline Total & 100 & 0.0600 & 100 & 32.4 & 100 & 18.6 \\
\hline
\end{tabular}


The total chloride concentration at Crater Lake is surprisingly small. This cannot be explained by any contamination or deficiency of the analytical methods and represents a reliable and important result. Since at the level of $700 \mathrm{mb}$ (Crater Lake) advection was clearly from the Pacific, the low chloride concentration must mean that sea salt was virtually absent above an altitude of about $2 \mathrm{~km}$, at least during the sampling period. Woodcock's (Junge, 1963) earlier data show essentially the same result, but his data were obtained in the subtropics under inversion conditions, where this can be expected.

To our knowledge, this is the first time the absence of sea salt at high altitudes has been shown for midlatitudes, although it has been found at higher and lower latitudes. Recent unpublished data on the snow composition of the Greenland ice cap have shown a lack of chloride above $1.5 \mathrm{~km}$. This agrees with earlier data obtained from the central part of the ice cap (Junge, 1960). There are at least four mechanisms which could account for the very low chloride concentrations observed at Crater Lake as compared to the high values found at Cape Blanco. These are: 1) differences in origin, e.g., continental vs maritime; 2) washout by rainfall between the two locations; 3) prevention of penetration of sea-salt particles to higher levels by atmospheric stability; and 4) removal of chloride from the higher layers of the maritime atmosphere. Since winds were generally from the west and there was little rain during the period of chemical sampling at Crater Lake, the first two explanations do not apply. The presence of a strong inversion below the altitude of Crater Lake was certainly a factor on 28 October. On the other four days, the Medford soundings show some afternoon stability below the Crater Lake level, but it was not very pronounced. Several weak disturbances passed through the area during the sampling period and the Pacific high pressure cell was well to the south. Thus, we do not believe that atmospheric stability insulated the level of Crater Lake from lower levels. Washout and rainout, however, are mechanisms that could prevent sea spray from reaching higher levels over mid-latitude ocean areas. Ocean surface air is always rather humid; therefore, convection is almost always accompanied by cloud formation, and oceanic clouds are very efficient rain producers (Squires and Twomey, 1960). This contrasts with convection over land which occurs in much drier air, especially during summer. It thus appears that a lack of sea-spray aerosol may be a general characteristic of the higher levels of maritime air masses.

For Crater Lake the chloride distribution is similar to that of sulfur but lower by a factor of about 8 . The ratio $\mathrm{Cl}^{-} / \mathrm{SO}_{4}=$ is completely different from that of sea salt, which clearly indicates the non-maritime origin of this aerosol.

In the two samples from Cape Blanco about $95 \%$ of the mass of chloride is concentrated at $r \geqslant 1 \mu \mathrm{m}$, indi- cating that sea-salt aerosols are almost completely restricted to this size range. This agrees with the conclusions drawn from Fig. 3 and the size distribution differences between Cape Blanco and Crater Lake.

The relatively high Cape Blanco chloride concentrations for $r \leqslant 1 \mu \mathrm{m}$, as compared with those of Crater Lake, may indicate that there is some production of these smaller sea-salt particles. However, the analyses of chloride in this range, particularly for sample 2), appear somewhat unreliable. It would be an important point to recheck. If the data are correct, one must conclude that these smaller sea-salt particles are just as efficiently removed over the ocean in higher layers as the larger ones, since the chloride level at Crater Lake in this size range is so much lower.

\section{Conclusions}

These aerosol studies in remote areas of southern Oregon provided some suggestions about the nature of tropospheric background aerosols. The conclusions, however, must be considered tentative because the experimental and observational basis is sparse. Broadly speaking, we can distinguish three types of atmospheric aerosols in Pacific air masses of middle and lower latitudes. The first, the low-to mid-tropospheric aerosol, is characterized by size distributions that can be approximated by a power law with an exponent of 3 to 4 .

The second type, the surface marine aerosol, differs essentially from the first by the addition of the typical sea-spray component. It appears that in marine air masses the sea-spray component is not a factor at altitudes of about $2 \mathrm{~km}$, and thus is probably not important to any degree in higher layers even in the westerly wind belt. The sea-spray distribution is generally believed to have a maximum at around $0.5 \mu \mathrm{m}$ radius, if presented in the double logarithmic fashion as in our figures.

The aerosols of the high troposphere, the third type distinguishable from our data, are associated with subsidence and have much lower concentrations below $0.5 \mu \mathrm{m}$ radius. The power law size distributions of this type have smaller exponential values, around 2.' The fact that our subsidence size distributions agree with corresponding data from the $3000 \mathrm{~m}$ altitude in Hawaii indicates a rather uniform, widespread upper tropospheric aerosol. This aerosol may represent a further stage in the reduction and aging of continental aerosols. It must be expected that there will be transitions between the first and the third type.

The mid- and high-tropospheric aerosols are estimated to be representative of about $80 \%$ of our troposphere on a global basis. They form the background conditions on which the low-level continental (natural sources, pollution) and maritime (sea-spray) aerosols are superimposed. More and better data are needed to confirm this concept of tropospheric aerosols. 
Acknowledgments. This work was supported by The Atmospheric Physics and Chemistry Laboratory, Environmental Sciences Services Administration, under Contract No. Cwb-11151.

\section{REFERENCES}

Bullrich, K., R. Eiden, R. Jaenicke and W. Nowak, 1966: Optical transmission of the atmosphere in Hawaii, II. Final Tech. Rept., J. Gutenberg U., Mainz, Germany, Contract No. DA-91-591-EUC-3458, 79 pp.

Coulson, D. M., and L. A. Cavanagh, 1960: Automatic chloride analyzer. Anal. Chem., 32, 1245-1247.

Day, G. J., 1955: Some airborne observations of condensation nuclei concentrations. Geophys. Pura Appl., 31, 169-181.

Friedlander, S. K., 1960: Similarity considerations for the particle size spectrum of a coagulating sedimenting aerosol. $J$. Meteor., 17, 479-483.

Hodkinson, J. R., and J. R. Greenfield, 1965: Response calculations for light-scattering aerosol counters and photometers. A ppl. Optics, 4, 1463-1474.

Junge, C. E., 1960: Sulfur in the atmosphere. J. Geophys. Res., 65, $227-237$.

- 1961: Vertical profiles of condensation nuclei in the stratosphere. $J$. Meleor., 18, 501-509.
- 1963 : Air Chemisiry and Radioactivity. New York, Academic Press, $382 \mathrm{pp}$.

__ 1966: Studies of the chemistry of unpolluted atmospheres. Final Rept., Stanford Research Institute, Menlo Park, Calif., Contract No. Cwb-11151, 98 pp.

Kleinschmidt, E., 1935: Handbuch der Meteorologischer Instrumente. Berlin, Julius Springer, $256 \mathrm{pp}$.

Lettau, H., 1939: Kern und Staubgehalt der Bodenluft und die atmosphärische Schwächung der Sonnenstrahlung über Afrika und den angrenzenden Meeren. Beitr. Geophys., 55, 105-137.

Ludwig, F. L., and E. Robinson, 1965 : Size distribution of sulfurcontaining compounds in urban aerosols. J. Colloid Sci., 20, 571-584.

$\ldots$, and ——, 1968: Variations in the size distributions sulfurcontaining compounds in urban aerosols. Atmos. Environ., 2 , 13-23.

Squires, P., and S. Twomey, 1960: The relation between cloud droplet spectra and the spectra of cloud nuclei. Physics of Precipitation, Washington, D. C., Amer. Geophys. Union, 211-219.

Whitby, K. T., and R. A. Vomela, 1967: Response of single particle optical counters to nonideal particles. Environ. Sci. Tech., 1, 801-814. 